\title{
Model for Targeting Customers Based on Analytics in Telecom Domain
}

\author{
Inderpreet Singh \\ Engineer, Product Development, Mahindra Comviva, Gurgaon, Haryana, India \\ Email: inderpreet.singh993@gmail.com \\ Sukhpal Singh \\ Computer Science and Engineering Department, Thapar University, Patiala, Punjab, India, 147004 \\ Email: ssgill@thapar.edu
}

\begin{abstract}
Big data has emerged as an important paradigm for analyzing and predicting customer's behavior. Based on the customer's behavior various campaigns are made to target them. This paper presents a model for telecom companies which will insist them in how to target customers based on analyses of their data collected. Proposed model gathers information from various customers through preconfigured devices and then it manages and provides required insights to telecom companies on basis of which they can target customers of particular segment. Its feedback model in which companies can change their campaign strategy according to the response they receive in real time.
\end{abstract}

Index Terms-Model, Analytics, Segmentation, Targeting Customers, Telecom Analysis

\section{INTRODUCTION}

In current scenario of business world, companies need to find innovative ways in order to differentiate themselves from their competitors. They need ability to respond to customer needs in as less time as they could. Many companies have data they needed but they lack in proper model to utilize it [1]. So, analytics on big data plays a crucial role in today's business world.

Big data widely refers to the new technologies and methods for collecting, storing and managing the vast amount of data whether it is structured data or unstructured data [12]. And then analyzing this data collected in real time to make impact on the customer behavior.

The big data is increasing day by day at a very rapid rate, causing data related challenges for the organizations [13]. For instance, there is the challenge of managing huge amounts of data i.e. big data, which is increasing day by day because of cheaper storages available in the market and transformation of digital data and information collection devices, such as smart phones, laptops, and sensors [14]. For example, social networking website Facebook is a repository of 40 billion photos, and U.S (United States) large retailer Wal-Mart handles more than 24 million customer transactions every day.
As more people interact with information the more information is shared. More than 1 billion people Worldwide entered the category of middle class according to the Economist Report [8] between 1990 and 2005 , and the amount of data transferred over the internet will surpass 667 Exabyte's annually by 2014 .

According to Cisco the amount of data continues to grow faster as compared to the amount which can be carried by the networks. To ease the data storage problems due to this exponential growth of data; many companies like Amazon's Web Services, Intel, AT\&T(American Telephone and Telegraph Company), Synaptic, IBM(International Business Machines) are providing various types of clouds services [15]. Besides the challenges posed by exponential growth of data, there are also opportunities like context-specific aggregation and analysis of data. For example, information extracted from digital records can make doctors' job easier in accurately diagnosing the disease and hence curing it, which in turn will bring down the healthcare costs to nominal. Hence, improving overall efficiency of the healthcare system [10]. Similarly, digitized data can be used for fighting crime and terrorism effectively by analyzing the data corresponding to every person in the world.

The innovations in communication networks especially smart phones technology have made them prone for wide range of applications [7]. Although, telecom companies are moving large amount of data around their networks for years but in current scenario these networks of telecom companies have seen unprecedented changes in terms of volumes of data which now consists of data related to video, social networking etc. [16]. Now, there are 4.6 billion mobile-phone subscriptions worldwide and 1-2 billion people use the internet [9]. So, we are living in an era of data explosion.

Telecom companies have more data as compared to other companies as they control the infrastructure through which the information flows. Almost $70 \%$ of all mobile data traffic will be from video by 2021 [11]. With the use of data acquisition and analytics techniques, this large amount of data can be used to help companies in gaining insights of consumer's behavior and hence getting competitive edge in the market [17]. As the final goal of 
telecom company is to forge closer and deeper relationships with customers so that company can maximize the lifetime value of customers [5]. Also, smart phone based crowd-sensing [9] can help the telecom company to leverage the superfluity of sensors in smart phones to collect information from a group of smart phone users and analyze this collected information for the benefit of the group.

So, telecom companies need an effective model for not only predicting the customer behavior but also to design, execute and analyze the campaigns for targeting the customers.

Considering the above mentioned scenario, objectives and significance of this paper can be summarized below

\section{A. Research Issues}

The paper attempts to answer the following three questions:

1. Which data is needed in order to predict customer behavior?

2. How to gather this data from various resources?

3. How to use this data for targeting the customers?

\section{B. Research Goal}

The goal is make an efficient model for telecom companies in order to target the customer on basis of their data. This model emphasizes the importance of predicting customer behavior using analytics for generating revenues and getting edge in the telecom market.

Not only this model predicts the customer behavior, it also has functionality of giving real time feedback to the telecom organization. So that campaigns used to target the customers could be effectively modified in very less time.

\section{Significance}

The significance of this paper lies in the fact that it aggressively gives the strategy to target the customers for the telecom companies and the importance of continuous feedbacks while executing the various campaigns in real time.

\section{ASSETS}

The main asset of any telecom company is data which can be leveraged to get better insights. This data can be structured or unstructured and it can be used for identifying not only right customer but also to serve contextually relevant offers [18]. Now for this, telecom companies need to combine unstructured data along with structured data.

\section{A. Structured Data}

Structured data is the data that could be associated with particular field and handled easily by the computing resources. The set of structured data that we need in our model to provide detailed consumer insights is mentioned below in Table.1.-

Table.1. Structured Data

\begin{tabular}{|c|l|l|}
\hline \multicolumn{2}{|l|}{ Structured Data } & Purpose Of Data \\
\hline S.No & Data Needed & Basic Information \\
\hline 1 & Name & $\begin{array}{l}\text { Differentiate Consumer on basis of } \\
\text { sex }\end{array}$ \\
\hline 2 & Age & $\begin{array}{l}\text { Differentiate consumer profiles on } \\
\text { basic high income, average income } \\
\text { and low income }\end{array}$ \\
\hline 5 & $\begin{array}{l}\text { Number Of } \\
\text { Minutes Used }\end{array}$ & $\begin{array}{l}\text { Total Duration Of calls, used for } \\
\text { targeting on basis of call plans }\end{array}$ \\
\hline 6 & $\begin{array}{l}\text { Number Of } \\
\text { Messages }\end{array}$ & $\begin{array}{l}\text { Details of messages sent and } \\
\text { received, used for targeting on basis } \\
\text { of message packs }\end{array}$ \\
\hline 7 & $\begin{array}{l}\text { International } \\
\text { Usalls }\end{array}$ & $\begin{array}{l}\text { Total Duration of international calls, } \\
\text { used for targeting on basis of } \\
\text { International Call Plans }\end{array}$ \\
\hline
\end{tabular}

\section{B. Unstructured Data}

Unstructured data usually has irregularities and ambiguities, which makes difficult for the traditional resources to handle .The set of unstructured that we need is mentioned below in Table.2.-

Table.2. Unstructured Data

\begin{tabular}{|l|l|l|}
\hline Unstructured Data & Purpose Of Data \\
\hline S.No & Data Needed & $\begin{array}{l}\text { Details customer } \\
\text { complaints and } \\
\text { feedback i.e. How much } \\
\text { satisfied is the customer } \\
\text { is }\end{array}$ \\
\hline 2 & Call center interaction & $\begin{array}{l}\text { To target particular } \\
\text { geography in the city }\end{array}$ \\
\hline 3 & Xeo spatial & $\begin{array}{l}\text { Captures data of } \\
\text { purchase and download } \\
\text { of apps etc. }\end{array}$ \\
\hline 4 & Social Media Data & $\begin{array}{l}\text { To study consumer } \\
\text { behavior from social } \\
\text { network }\end{array}$ \\
\hline
\end{tabular}

\section{MODEL FOR TARGETING CUSTOMERS}

This model is focused on recognizing customers; designing campaigns for distinct customer segments, executing campaigns and analyzing effectiveness of marketing spend to get maximum customer value. The framework grounded in this real-time model can help "finding customers for products" to "finding the right products for customers".

This model consists of series of activities for targeting the customers on basis of different customer segments and then evaluating the results. It has four steps-

\section{A. Recognize}

Customer data is the new currency to the business growth. Telecom companies need to focus on discovering the unique characteristics of their customers, understand 
what they purchase and why they purchase their specific products. This data related to the use of consumer mobile network services must be captured in real time for immediate use.

This phase starts with recognizing the different segments of customer (on basis of data gathered and analyzed) for whom various campaigns will be designed and executed. Customers are segmented not only on basis of RFM(Recency Frequency Monetary) analysis but also on the basis of their location, social media data and data usage pattern. And finally, data related to various segments is stored on cloud.

\section{B. Design}

Telecom companies need to leverage insights in order to create relevant campaigns for the customer. Customers with more usage and potential churn customers are closely targeted by the campaigns as they are the most relevant opportunity through most effective channel at most effective time, as they are on which profitability of company lies.

In this phase contextual campaigns are designed to target the customers of various segments, which are recognized in the first phase. Each campaign is designed to target particular segment individually. The various parameters related to campaign like number of days it will be implemented, the frequency etc. also gets decided in this phase.

\section{Implement}

Telecom companies need to pay attention on efficient automation of the campaign management process and ensuring that campaign execution is at proper time from the customer's point of view. The companies need to deliver the precise offers based on customer transactional triggers. For example, customers may experience dropped calls or no network and call the customer care center. The customer care center representative is alerted that this customer has experienced difficulty. Before the customer describes his frustration, the representative should be able to pre-empt the ongoing discussion by acknowledging the problem and make a special offer through real time system.

In this phase, various campaigns are implemented which were designed for particular segments of customer. In it, telecom companies tracks the customer activity in real time and delivers the campaign at right time using the multiple channels. The customer related data along with his or her response to the campaign gets stored in the company's databases.

\section{Analyze}

In this last phase, campaigns are analyzed to assess the campaign success and make desired improvements in campaign for real time effectiveness of it. Each time when the operator company makes a campaign, the customer does something in response. And feedback of that response is send back in real time to the telecom company which analyses the performance of their campaign and make adequate changes in the campaign.
This action and reaction is a learning relationship in which telecom companies learn more about the customer behavior which helps the telecom companies in making the effective improvements in their campaigns.

\section{ARCHITECTURE OF MODEL}

Fig. 1 presents a model for telecom companies which will insist them in how to target customers based on analyses of their data collected.

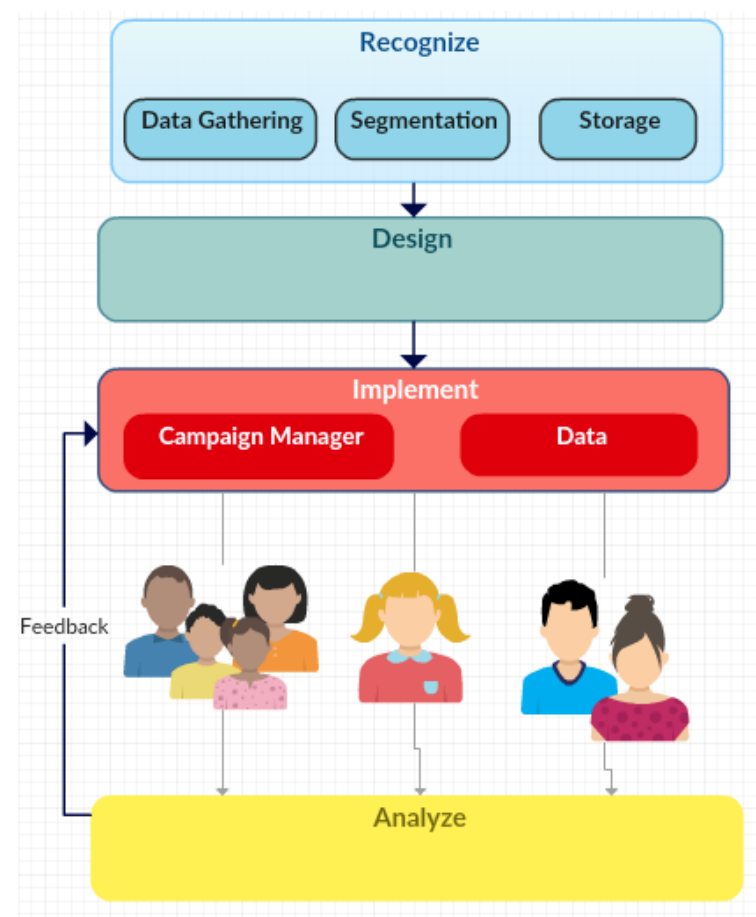

Fig.1. Architecture of Model for Telecom Companies

\section{A. Recognize}

This phase consists of recognizing the different customer segments for implementing the campaigns designed specifically for them. It consists of following activities as mentioned in Fig.2.-

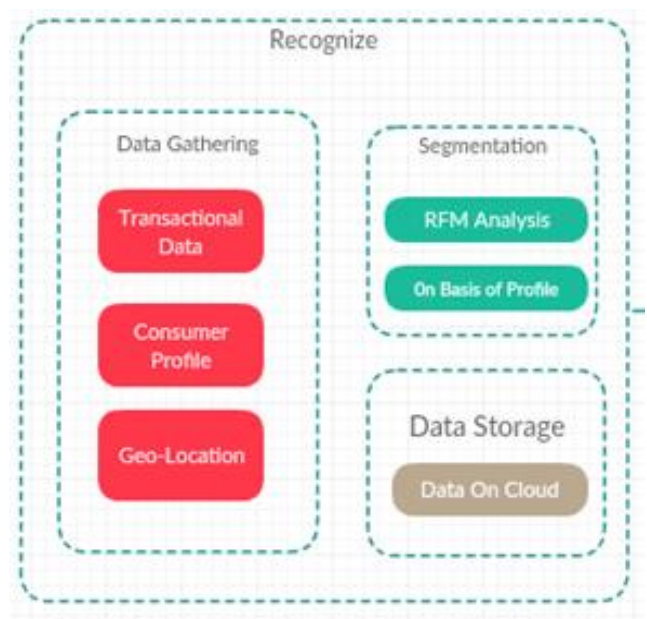

Fig.2. Recognize Phase of Model 


\section{Data Gathering}

In this step, data is gathered related to customer whether it's transactional data, profile data or GeoLocation of the customer. Transactional data can be easily gathered from the telecom company's databases which contains the records related to total time of calls made, total usage of internet data etc.

The profile data can be gathered through the customer registration form which he or she fills while registering for the telecom operators services. Profile data can also include social media data which can be easily fetched by use of twitter API's(Application program interface) or through customers posts on Facebook pages of company's page.

And last but not the least, Geo-Location of customers can be got through the combination of global positioning system and Wi-Fi positioning system. Wi-Fi positioning system is used in case of buildings where GPS does not works well because of obstructions in the line of sight with the satellites [3].

\section{Data Storage}

The data collected related to customer will be now stored on the cloud. As data is growing at rapid rate that we can't predict the upper limit, so storing this enormous data on the cloud is the only solution [4]. Telecom companies can access and analyze this data anywhere by making use of API's which processes the data and give the detailed insights as an output.

\section{Segmentation}

In this step, customers are divided into various segments, not only on basis of RFM analysis but also on the basis of their profile i.e. customers located at particular location at particular time of the day.

With the use of RFM analysis, telecom companies can know who the high value customers are and who potential churn customers are. Along with these, they can also segment the customer on basis of talk time or internet data etc. RFM analysis is done on transactional data records stored on the database related to each and every customer.

Through the use of location, telecom companies can segregate the customers present in particular location from the others. So it helps in creating segments of the customers, location wise.

\section{B. Design}

In this phase various campaigns are designed to target specific segment of customers. A customer can appear on one or more segment. These can campaign cannot only target high value customers, potential churn customers but also the location based, age based, profession based different segments of customers. Few examples of the campaigns are mentioned below-

\section{Location based Advertisement Campaigns}

Telecom companies can get associated with other companies to run their advertisements. These Advertisement then run on the different apps showing how many kilometers a customer is away from the particular store.

When the customer clicks on it, then it will display on offer along with the direction to the store. In this way, telecom companies can have access to consumer buying behavior. They use geo-location of consumer along with the location of the store (to which they are associated with) to generate income from these advertisements.

\section{Subsidized rates at night}

Usually at night time, the revenue of telecom companies drops due to reduced usage of their services by the customers. So telecom companies can provide their services to the customers at very low rate which will be resulting in increased revenue for the companies.

\section{Campaigns for the potential churn customers}

Potential churn customers are the ones who will be ceasing their relationship with the company in nearby future. They can be identified with the use of RFM analysis. Free data pack and limited talk time for specific period of time can be offered to potential churn customers, so that to reduce the rate of customers leaving or company. As huge costs are associated with them as described in Equation (1),

$$
\begin{gathered}
\text { Total Cost }(\text { Customer Churn })=\text { Lost Revenue } \\
+ \text { Marketing Cost }
\end{gathered}
$$

\section{Campaigns for high value customers}

High value customers are those on which telecom company's profitability depends. They are the customers due to which company exists in the market. Campaigns must be designed specifically for them. These campaigns not only provide them low cost offerings of the company's services to them but also loyalty in terms of points to them.

\section{Implement}

In this phase, the campaigns designed specifically for each of the segment of the customer are implemented. For this usually company employs a campaign manager system along with customer response data, so that campaign can be changed in real time according to the customer's response. The two categories of this phase are shown in below Fig.3.-

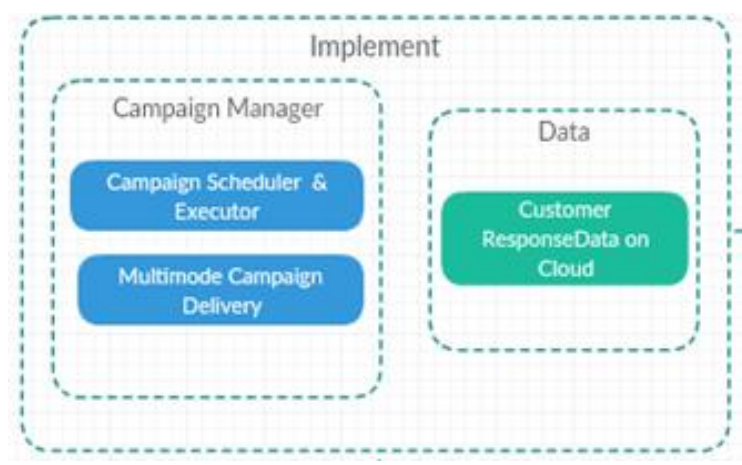

Fig.3. Implement Phase of Model 


\section{Campaign Manager}

Telecom companies need to focus on defining and automating the campaign management process, which is the task of campaign manager. Campaign manager is not only responsible for execution of campaign but it also takes care of different modes through which campaign needs to be delivered to the customers. It interacts with customer response data to get the results of customer feedback and based on these results it tries make effective increments in the campaign.

\section{Customer Response Data}

Customer response data is the data related to the response of customer to the campaign that get stored in company's databases. These databases are on the cloud as there is no upper limit on this data .So to count as scalability as an important factor these databases are usually on cloud platform.

\section{Analyze}

The last phase of this model is the analyze phase as shown in Fig.4. In this phase, various insights related to customer's response will be generated. Reports related to the campaign success also get generated in this phase. This phase is important as it tells the telecom companies that how much their campaign is successful and based on these insights, companies can make improvements in their campaign.

In addition, this phase not only evaluates each marketing initiative but also compares it with others initiatives in the present business market. Business market optimization and case planning could be used to optimize future marketing strategies at the world level, and can also be used to improve the performance of future initiatives by the telecom organization in this particular area.

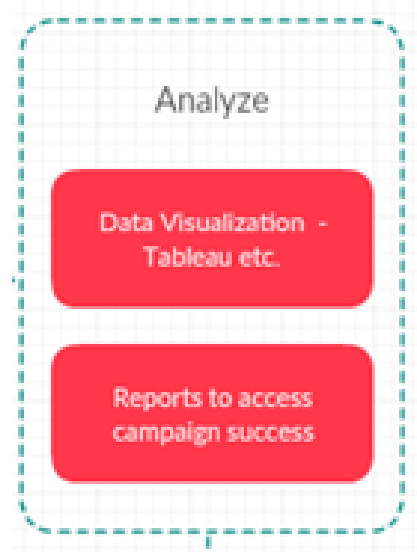

Fig.4. Analyze Phase of Model

\section{IMPLEMENTATION}

As we discussed the architecture of model ranging from the recognize phase to analyze phase. Now we will be discussing in this section, how this model could be implemented in any telecom organization. We will be also discussing about the feedback of the customers not only from the campaign performance parameters but also from their interaction with the customer care center.

This model will be translated into the following phases in the organization as shown in Fig.5.-

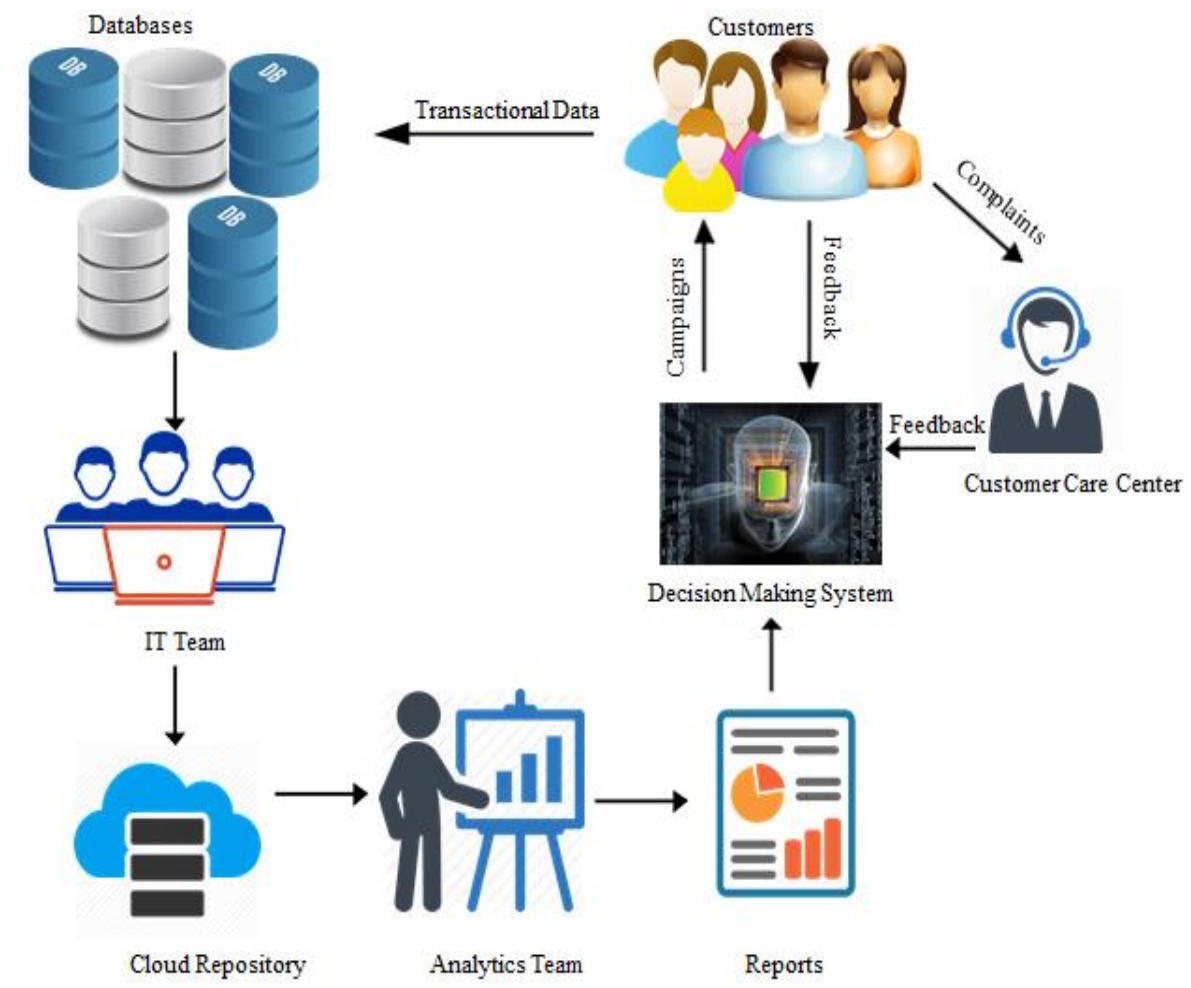

Fig.5. Implementation of Model in Telecom Industry 


\section{A. Databases}

Databases store the data from various sources like data related to customer mobile usage, customer profile, current location, social network data etc. Customer mobile usage data will be collected from the various transactions done by the customer like voice call, internet usage, messages etc.

The profile data can be gathered through the customer registration form which he or she fills while registering for the telecom operators services.

The current location data is collected not only from customer's Geo-Location but also from Wi-Fi positioning system.

And finally customer's social network data is collected from the customer's profile on Twitter or Facebook with the help of their API's.

\section{B. IT Team}

Information Technology (IT) team is responsible for extracting the relevant data like mobile usage data, customer present location data from the databases. This data is then stored on the repository which is on cloud. On this data analytics team perform the analysis.

\section{Cloud Repository}

The importance of usage of cloud repository is that from it data can be accessed anywhere at any time. Moreover, in case of cloud repository storage issues are also resolved as organization can get as much as space needed.

\section{Analytics Team}

Analytics team composing of data scientists and data analysts then extracts the information of many customers from the cloud repository. Then, they run analyses on this data to form various segments of the customer. And finally generate the reports (with the help of tools like Tableau, Petaho, MS-Word) related to various segments as needed by decision making system team.

\section{E. Reports}

Reports consist of various reports related to various segments. These reports have brief analysis not only of customer transactional data but also of their profile data as well as their social network and location data.

\section{F. Decision Making System Team}

Decision making team will then design campaigns for various segments. Not only then they will deliver these campaigns but also measure the performance of each campaign in real time. On basis of performance and customer's feedback from the customer care center they will take actions in very quick time.

\section{CONCLUSION}

In this section, we will firstly summarize the main contributions of our work and then enlist the limitations and future research directions

\section{A. Conclusion-}

Today, most organizations are fundamentally dependent on their data and information handling services facilitated by their computing resources [6] to collect, store, manage and finally, analyze data better. In this paper initially, we have provided a list of data-structured and unstructured which we will be needed as input for model in order to address telecom companies today's and tomorrow's needs. And then we have proposed a conceptual model for telecom companies which will help them in telling how to analyze and target the customers better to get competitive edge in current complex market.

\section{B. Limitations and future work-}

There are additional theories that we have not addressed fully. For example- we have not discussed how real time response gets generated and evaluated. Secondly, how we will make efficient use of both structured and unstructured data collected in decision making process of campaign designing. Thirdly, how should we educate new data analysts, data scientists, DBA's and users for applying analytics on big data which is stored on cloud?

\section{REFERENCES}

[1] M. Bylehn, "Ericsson Mobility Report: mobile data growth to skyrocket by 2021", ConsumerLab, data, Ericsson Mobility Report, 2015

[2] H. Baars and H.G. Kemper. "Management support with structured and unstructured data-an integrated business intelligence framework." Information Systems Management Vol. 25, no. 2 (2008): pp.132-148.

[3] B. Li, P. Mumford, A. G. Dempster, and C. Rizos. "Secure User Plane Location: concept and performance." GPS solutions Vol. 14, no. 2 (2010): pp.153-163.

[4] $\mathrm{Ma}, \mathrm{Li}$, and M. Jiang. "Chances and challenges confronting securities industry and the countermeasures in big data and cloud computing era." InComputer Science \& Education (ICCSE), 2014 9th International Conference on, pp. 177-182. IEEE, 2014.

[5] D. Peppers, M. Rogers, and B. Dorf. "Is your company ready for one-to-one marketing." Harvard business review 77, no. 1 (1999): pp. 151-160

[6] J. Peppard "Managing IT as a Portfolio of Services." European Management Journal Vol. 21, no. 4 (2003): pp. 467-483.

[7] G. Goggin. "Cell phone culture: Mobile technology in everyday life." Routledge, 2012.

[8] T. Economist "Data, data everywhere: A special report on managing information." The Economist (2010).

[9] P.P Jayaraman, C. Perera, D. Georgakopoulos, and A. Zaslavsky. "MOSDEN: a scalable mobile collaborative platform for opportunistic sensing applications." arXiv preprint arXiv: 1405.5867 (2014). 
[10] D. Delen, A. Oztekin, and L. Tomak. "An analytic approach to better understanding and management of coronary surgeries." Decision Support Systems Vol. 52, no. 3 (2012): pp. 698-705.

[11] S. Singh and I. Chana. "EARTH: Energy-aware autonomic resource scheduling in cloud computing." Journal of Intelligent \& Fuzzy Systems Vol. 30, no. 3 (2016): pp. 1581-1600

[12] S. Singh and I. Chana. "Resource provisioning and scheduling in clouds: QoS perspective." The Journal of Supercomputing Vol. 72, no. 3 (2016): pp. 926-960.

[13] S. Singh and I. Chana. "QoS-aware autonomic resource management in cloud computing: a systematic review." ACM Computing Surveys (CSUR) Vol. 48, no. 3 (2016): pp. 42.

[14] S. Singh and I. Chana, "QRSF: QoS-aware resource scheduling framework in cloud computing", "The Journal of Supercomputing", [Springer], Vol. 71, no. 1, pp: 241292, 2015.

[15] Kamala, S. Praveena Rachel, and S. Justus. "Towards MORK: Model for Representing Knowledge." International Journal of Modern Education and Computer Science Vol. 8.3 (2016):pp. 45.

[16] M. S. Iraji, H. Maghamnia, and M. Iraji. "Web Pages Retrieval with Adaptive Neuro Fuzzy System based on Content and Structure." International Journal of Modern Education and Computer Science Vol. 7.8 (2015):pp. 69.

[17] K. Kajitori, K. Aoki, and S. Ito. "Developing a Compact and Practical Online Quiz System.” International Journal of Modern Education and Computer Science Vol. 6.9 (2014):pp. 1.

\section{Authors' Profiles}

Inderpreet Singh has obtained the Degree of Bachelor of Engineering in Computer Science from Thapar University, Patiala. Presently he is working as an EngineerProduct Development in Mahindra Comviva, Gurgaon. He has done certifications in PostgreSQL , Cloud Computing and Python Fundamentals. His research interests include Analytics, Data Mining, Predictive Modeling and Cloud Computing.

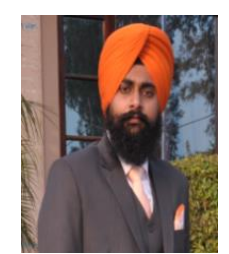

Sukhpal Singh joined Computer Science and Engineering Department of Thapar University, Patiala, India, in 2016 as Lecturer Dr. Singh obtained the Degree of Master of Engineering in Software Engineering from Thapar University, as well as a Doctoral Degree specialization in "Autonomic Cloud Computing" from Thapar University,. Dr. Singh received the Gold Medal in Master of Engineering in Software Engineering. Dr. Singh is a DST Inspire Fellow [2013-2016] and worked as a SRF-Professional on DST Project, Government of India. He has done certifications in Cloud Computing Fundamentals, including Introduction to Cloud Computing and Aneka Platform (US Patented) by ManjraSoft Pty Ltd, Australia and Certification of Rational Software Architect (RSA) by IBM India. His research interests include Software Engineering, Cloud Computing, Operating System and Databases. He has more than 30 research publications in reputed journals and conferences.

How to cite this paper: Inderpreet Singh, Sukhpal Singh,"Model for Targeting Customers Based on Analytics in Telecom Domain", International Journal of Modern Education and Computer Science(IJMECS), Vol.8, No.11, pp.43-49, 2016.DOI: $10.5815 /$ ijmecs.2016.11.06 